\title{
PEREMPUAN MINANGKABAU DALAM PANGGUNG POLITIK
}

\author{
Lindayanti*
}

\begin{abstract}
ABSTRAC
Women in the Minangkabau indigenous community structure have a unique role. In the Minangkabau matrilineal custom system, women are placed in a central position. Minangkabau women have been portrayed as having played a role in the political arena in Minangkabau for a long time. This can be seen from classic Minangkabau stories such as kaba, tambo or myth. Many stories of women's heroism are found. What is the relationship between the ideal level and reality in the politics of Minangkabau women? For example, "Keagungan Bundo Kanduang" depicted in the story of Cindur Mato from an ideal level coupled with Minangkabau women performing in various fields such as Putri Rahmah el Yunusiyah also established several other women's schools as an effort to increase the education level of women in Minangkabau.
\end{abstract}

Keyword: Minangkabau, political, and women.

\begin{abstract}
ABSTRAK
Perempuan dalam susunan masyarakat adat Minangkabau memiliki peranan yang khas. Dalam sitem adat matrilineal Minangkabau, perempuan ditempatkan dalam posisi sentral. Perempuan Minangkabau digambarkan berperan dalam percaturan politik di Minangkabau sejak lama. Hal ini dapat dilihat dari ceritera klasik Minangkabau seperti kaba, tambo ataupun mitos. Banyak kisah kepahlawanan perempuan ditemukan. Bagaimanakah hubungan antara tataran ideal dan realita dalam perpolitikan perempuan Minangkabau ? Misalnya, Keagungan Bundo Kanduang yang digambarkan dalam ceritera Cindur Mato dari tataran ideal bersanding dengan perempuan Minangkabau tampil dalam berbagai bidang seperti Putri Rahmah El Yunusiyah juga mendirikan beberapa sekolah perempuan lainnya sebagai usaha dalam rangka meningkatkan tingkat pendidikan kaum perempuan di Minangkabau.
\end{abstract}

Kata Kunci: Minangkabau, Perempuan, dan Politik.

\section{A. Pendahuluan}

Perempuan selalu menjadi topik yang tidak kunjung usai dibahas, diteliti

dan diperbincangkan, tak terkecuali perempuan Minangkabau. Perempuan

\footnotetext{
* Dosen Sejarah Universitas Andalas Padang.
} 
dalam susunan masyarakat adat Minangkabau memiliki peranan yang khas. Sistem kekerabatan matrilinial atau benasab kepada ibu menjadi pembeda yang kontras terkait posisi perempuan Minang dengan suku-suku lain yang ada di bumi Nusantara.

Realitas masyarakat menunjukkan kecendrungan untuk menjadi global. Geliat perubahan zaman terasa begitu dinamis. Tentu saja hal ini turut mempengaruhi tatanan masyarakat Minang. Modernitas adalah sesuatu yang ikut merasuki relung-relung kehidupan perempuan Minangkabau. Batas yang tegas antara peradaban Barat dengan Timur terasa begitu kering untuk dijadikan pondasi dalam menganalisis praktis kehidupan perempuan Minang. Karena sejatinya, setiap gejala yang terjadi di Barat sana, tinggal menunggu persoalan waktu untuk sampai pada kehidupan anak nagari Minangkabau.

Ketika orang berbicara tentang perempuan Minangkabau yang terbayang adalah adat dan budaya Minangkabau menghormati posisi perempuan. Hal ini sejalan dengan persepsi budaya Minangkabau mengandung nilai-nilai demokratis termasuk untuk kalangan perempuan. Dalam sitem adat matrilineal Minangkabau, perempuan ditempatkan dalam posisi sentral. Perempuan Minangkabau digambarkan berperan dalam percaturan politik di Minangkabau sejak lama. Hal ini dapat dilihat dari ceritera klasik Minangkabau seperti kaba, tambo ataupun mitos. Banyak kisah kepahlawanan perempuan ditemukan. Misalnya, berdasarkan ceritera yang diwariskan secara turun temurun digambarkan tentang keberadaan Bundo Kanduang yang memiliki kekuasaan menetapkan arah kebijakan dan keputusan-keputusan kerajaan. Seperti yang digambarkan dalam paragraph pertama ceritera Cindur Mato adalah mengenai keagungan Bundo Kanduang. Bundo Kanduang adalah ratu yang kedudukannya 'tidak dibeli dan juga tidak diminta' ratu asli yang berdiri dengan sendirinya yang muncul bersamaan dengan alam Minangkabau. "Bundo Kanduang imbangan Raja Rhum, imbangan Rajo Cino, imbangan Rajo Samudra."1 Posisi Bundo Kanduang merupakan sumber kebijakan bagi

1 Taufik Abdullah, "Some Notes on The Kaba Tjindua Mato: An Example of Minangkabau, Traditional Literature dalam Indonesia 9 April 1970. 
kerajaan Pagaruyung meskipun demikian Bundo Kanduang tidak dapat mengambil keputusannya sendiri. Bundo Kanduang tidak memiliki jabatan resmi dalam hirarki sistem politik Minangkabau. Persetujuan senantiasa diperlukan dalam hal apapun yang diputuskan Rajo Buo Selo dan Basa Ampek Basa.

Berdasarkan konstitusi adat Minangkabau Bundo Kanduang merupakan salah satu bagian dari lembaga adat nagari. Berdasarkan konstitusi adat Minangkabau "bundo kanduang, limpapeh rumah gadang, nan gadang basa batua, umbun puro pegangan kunci, umbun puro aluang bunian, pusek jalo kumpulan tali" Intinya sebuah bentuk pengakuan tentang besarnya kekuasaan seorang ibu dalam rumah gadang atas harta benda dan hidup keturunannya. Begitu besar kekuasaan ibu bahkan seorang penghulu pun harus tunduk kepadanya. Selanjutnya, bagaimanakah hubungan antara tataran ideal dan realita dalam perpolitikan perempuan Minangkabau?

\section{B. Pergeseran Dari Ranah Domestik ke Ranah Publik}

Perubahan terjadi di Minangkabau setelah Perang Paderi dengan diterapkannya 'tatanan adat di atas landasan agama' atau yang disebut dengan adat basandi syarak, syarak basandi kitabullah. Dengan memakai prinsip ini penilaian tentang adat harus mengacu kepada hukum Islam dan ulama lah yang memiliki hak-hak untuk menafsirkan dan menseleksi hukum adat yang cocok dengan hukum Islam.

Satu peristiwa penting yang mengawali munculnya gerakan reformasi adat dan agama adalah diperkenalkannya sistim pendidikan modern. Kaum pembaharu meminta perempuan agar menimba ilmu di surau-surau. Hal ini dilakukan untuk menahan perempuan tetap berada di kampungnya dan kedua agar perubahan perempuan tetap satu garis dengan ajaran-ajaran Islam. Sebelumnya hanya laki-laki yang diterima menjadi murid dan ketika surau membuka pintu bagi perempuan ternyata banyak perempuan memilih surau untuk menambah pengetahuan. 
Surau bagi perempuan Minangkabau memiliki nilai strategis tersendiri karena di surau sejak lama ulama memperdebatkan hak-hak dan wewenang perempuan sehubungan dengan sistim matrilineal yang dipakai masyarakat Minangkabau. Dengan demikian. perempuan pun dapat menggali dan memahami hukum-hukum Islam yang terkait hak-hak mereka.

Sampai dengan pergantian abad ke-20 kebanyakan orangtua menolak pendidikan Belanda karena sekolah mencampuradukan laki-laki dan perempuan. Hal ini dipandang oleh para pemimpin agama dan adat merupakan ancaman serius terhadap budaya Minangkabau. Perempuan Minangkabau disekolahkan di sekolah-sekolah pribumi akan tetapi untuk melanjutkan pendidikan ke tingkat yang lebih tinggi mengundang perdebatan kembali. Pihak yang menolak beralasan perempuan harus kembali ke kampungnya untuk menjaga harta pusaka yang diwariskan kepadanya. Dengan demikian pendidikan tinggi tidak dibutuhkan. Pihak yang setuju beralasan perempuan harus memakai kesempatan untuk memacu perkembangan diri agar lebih mampu dan lebih siap untuk menjalankan tugas yang dibebankan adat.

\section{Zaman Kemajuan dan Munculnya Tokoh dan Organisasi Perempuan}

Datuk Sutan Maharaja seorang pemimpin gerakan kaum muda yang menyebarkan ide-idenya melalui surat kabar 'Soenting Melajoe' merupakan penyokong bagi kemajuan perempuan. Dia memasukan saudara perempuannya, Ratna Djuita dalam kepengurusan surat kabar. Pada tahun 1909 Sutan Maharaja mendirikan Sekolah Kepandaian Putri di Padang. Tiga tahun setelah itu muncul sekolah sejenis sekitar 12 sekolah. $^{2}$

Rohana seorang guru anak kampung di Koto Gadang pada tahun 1911 mendirikan Kerajinan Amai Setia (KAS) untuk membantu perempuan memperoleh penghasilan sendiri. Perempuan selain sebagai pewaris harta pusaka tetapi mereka memiliki pendapatan sendiri. Dengan demikian perempuan sebagaimana laki-laki dapat memutuskan sendiri kehendak hidupnya. Di publik dia menuliskan'Kami perempuan Hindia tidak pernah

\footnotetext{
${ }^{2}$ Taufik Abdullah, Schools and Politics
} 
berpikir harus diperlakukan sama dengan laki-laki menempati pekerjaan dan posisi yang sama sebagai jaksa, dokter dan sebagainya. Apa yng kami tuntut adalah penghargaan terhadap kami sebagai perempuan. ${ }^{3}$

Rohana Kudus (1884-1972) yang memulai perjuangannya di bidang pendidikan dengan mendirikan sekolah kerajinan, Amai (Ibu) Setia, di kampuang halamannya pada tahun 1911. Ia juga berjuang di media massa sebagai pimpinan redaksi koran Soenting Melayoe yang didirikan oleh Sutan Maharadja di kota Padang tahun 1912. Koran ini membuka kesempatan luas bagi dirinya untuk memperjuangkan nasib perempuan di Hindia Belanda.

Selain Rohana Kudus, muncul pula nama Rasuna Said (1910-1965) ${ }^{4}$ sebagai tokoh perempuan yang banyak melibatkan dirinya dalam bidang politik. Keterlibatannya pada bidang politik tersebut merupakan bagian yang tidak terpisahkan dari aktivitasnya memperjuangkan perempuan pada masa pergerakan. Cita-cita besarnya untuk mengangkat harkat dan martabat perempuan diwujudkannya pula dengan memimpin sekolah kursus untuk perempuan di kota Padang. Selanjutnya ia mendirikan perguruan putri dan memimpin Majalah Menara Putri di Medan.

Awal perjuangan politik Rasuna Said dimulai dengan beraktivitas di Sarekat Rakyat (SR) sebagai sekretaris cabang. Rasuna Said kemudian bergabung dengan Soematra Thawalib dan Persatoean Moeslimin Indonesia (PERMI) di Bukittinggi pada tahun 1930. Selain itu dia juga aktif di Kursus Putrid an Normal Kursus di Bukittinggi. Selain sebagai guru Rasuna Said juga dikenal mahir berpidato dan pidatonya yang sering mengecam Belanda sehingga dia tercatat sebagai wanita pertama yang terkena hukum Speek Delict, bahwa siapapun dapat dihukum karena menentang Belanda. Rasuna Said sempat ditangkap bersama teman seperjuangannya Rasimah Ismail dan dipenjara di Semarang pada tahun 1932. Setelah keluar dari penjara Rasuna Said mengikuti pendidikan di Islamic College pimpinan KH Mochtar Jahja dan Dr. Kusuma Atmaja.

3 "Rohana, KAS" dalam Soeara Hindia, 1913.

4 Rasuna Said diangkat sebagai salah satu Pahlawan Nasional berdasarkan Surat Keputusan Presiden RI No. 084/TK/Tahun 1974 tanggal 13 Desember 1974. 
Saadah Alim seorang yang berpendidikan Barat dan pejuang emansipasi Minangkabau. Dia menyuarakan pemikirannya dalam Soeara Perempoean karena Saadah mengingkan perempuan Minangkabau ikut serta dalam gerakan perempuan di Jawa dan Indonesia. Adat Minangkabau tidak sesuai dengan emansipasi karena meskipun dalam adat Minangkabau perempuan memiliki status yang tinggi tetapi tidak demikian dalam kenyataannya, kebebasan mereka tidak ada artinya. Mereka hidup bak burung dalam sangkar. Apakah itu sebuah persamaan $?^{5}$

Hal yang berbeda terjadi pada Rahmah el Yunusijjah yang berkategori sebagai Muslim modern. Pemikiran Rahmah El Yunusiyah dalam pembaharuan pendidikan Islam di Minangkabau bisa dilihat dengan adanya pendirian Diniyah School Putri. Sebagai penunjang perguruan Diniyah School Putri Rahmah El Yunusiyah juga mendirikan beberapa sekola perempuan lainnya sebagai usaha dalam rangka meningkatkan tingkat pendidikan kaum perempuan di Minangkabau.

Kiprah dan pemikiran Rahmah el Yunusijjah tertuang dalam pembaharuan pendidikan Islam di Minangkabau. Pertama saat Rahmah mendirikan Diniyah School Putri (1923). Sebagai penunjang perguruan Diniyah School Putri Rahmah el Yunusijjah juga mendirikan beberapa sekolah perempuan lain yaitu Yunior Institut Putri (1938), Islamitisch Hollandse School (1940).

Selain itu memasuki abad ke-20 spirit kemajuan di Minangkabau mendorong banyak perempuan untuk mengambil bagian dalam pergerakan nasional. Munculya organisasi-organisasi perempuan seperti Vroewenbond Payakumbuh, Perkoempoelan Kaoem Iboe. Selanjutnya Sjarekat Kaoem Iboe Soematera (SKIS). Perkumpulan ini menghimpun perkumpulan-perkumpulan perempuan dan berdampingan dengan kelompok-kelompok perempuan yang tumbuh di nagari-nagari. Misi utama perkumpulan ini adalah: 1) memperkuat jalinan di antara perkumpulan perempuan untuk mengembangkan diri dan

${ }^{5}$ Abdullah, Taufik., "Modernization in the Minangkabau World," In C. Holt (Ed.), Culture and Politics in Indonesia, Ithaca: Cornell University, 1972. 
berakitivitas sebagai pendidik dan pemimpin; 2) mengembangkan kesetiaan perempuan sebagai ibu dan memperdalam adat istiadat, bahasa, ketrampilan, dan sejarah. ${ }^{6}$

SKIS menjalankan misinya dengan cara saling mendukung di antara perkumpulan-perkumpulan yang ada dan dengan menyediakan pelayanan pelatihan bahasa, pergelaran seni dan penerbitan-penerbitan. Sambil memajukan pengajaran agama, anggota-anggotanya juga diminta untuk mengajarkan aturan-aturan adat yang dikombinasikan dengan pengetahuan modern. Dalam hal ketrampilan mereka memberikan pelayanan berupa pelatihan menjahit, memasak, agama, dan berdebat, serta membentuk kelompok-kelompok belajar, mengadakan kegiatan oleh raga, kerajinan tangan dan mendirikan pusat-pusat kesenian.

Perempuan yang ingin masuk dalam dunia politik, publik, budaya dan sosial sering tidak bersahabat atau bahkan bermusuhan. Perjalanan yang harus dilalui oleh kaum perempuan untuk menuju kedudukan kepemimpinan politik ternyata penuh dengan berbagai rintangan, berliku, tidak mulus, dan bahkan terasa sangat sulit. Gagasan bahwa perempuan sebaiknya tidak melibatkan diri dalam urusan politik sudah bercokol lama. Di Sumatera Barat hambatan gerakan politik masyarakat terutama ruang gerak perempuan dalam politik telah dimulai sejak zaman penjajahan Belanda. ${ }^{7}$

Perjuangan perempuan Minangkabau dalam bidang politik ' hak pilih pasif' di Dewan Minangkabau. Hampir semua baik kelompok adat maupun kelompok agama keberatan dengan keberadaan perempuan di Minangkabauraad alasan mereka adalah bertentangan dengan adat dan agama. Pergeseran peran perempuan Minang juga disebabkan oleh modernisasi dan pergeseran adat di Sumatera Barat dan perubahan adat pada sistem budaya

${ }^{6}$ Ranny Emilia, Studi Konflik dan Perdamaian Memperbaiki Dunia Melalui Tangantangan Perempuan, Padang: Prodi Ilmu Hubungan Internasional Unand, 2008.

${ }^{7}$ Schrijvers, Joke dan Els Postel-Coster, 'Minangkabau women: Change in Matrilineal Society," dalam Archipel, Volume 13, 1977, hlm. 79-103. 
lama, dimana adanya perubahan dari rumah Gadang ke rumah Rakyat (Parlemen) dari segi kepemimpinannya.

Selain pendidikan, perempuan Minangkabau juga belum memiliki hak yang sama dalam bidang politik. Hal ini terungkap dalam berbagai artikel yang dimuat oleh surat kabar yang terbit Hindia Belanda pada awal abad keduapuluh, baik yang bersifat lokal maupun nasional. Salah satunya adalah Majalah Isteri Indonesia yang memuat artikel yang ditulis oleh Djoes'a Burhan dengan judul "Dewan Minangkabau Menolak Kaum Ibu ?" Artikel ini merefleksikan bahwa di Minangkabau yang menganut sistem matrilinial masih mengabaikan hak-hak perempuan. Tiga orang anggota Dewan Minangkabau, yakni S.M. Latief, Tjon Sin Soen dan Datoek Sakato, begitu kata Djoes'a Burhan, menolak kehadiran tokoh perempuan dalam dewan tersebut. ${ }^{8}$

Pada zaman kemajuan ini perempuan Minangkabau tampil dalam berbagai bidang antara lain bidang pendidikan, dan berbagai penerbitan, melalui media yang dipimpinnya mereka menyuarakan emansipasi dan dalam rubriknya mereka juga menghidangkan etiket perempuan dalam pergaulan di tengah masyarakat.

\section{Kesimpulan}

Kebanyakan orang ketika berbicara tentang perempuan Minangkabau berpersepsi bahwa adat dan budaya Minangkabau adalah menghormati posisi perempuan. Memang, dalam sitem adat matrilineal Minangkabau, perempuan ditempatkan dalam posisi sentral. Misalnya, perempuan Minangkabau digambarkan berperan dalam percaturan politik di Minangkabau sejak lama, yaitu terdapat dalam ceritera klasik Minangkabau seperti kaba, tambo, ataupun mitos. Namun, tidak demikian dalam kenyataannya, meskipun dalam adat Minangkabau perempuan memiliki status yang tinggi, tetapi adat Minangkabau tidak sesuai dengan emansipasi. Kebebasan mereka tidak ada artinya dan mereka hidup bak burung dalam sangkar.

8 Blackwood, Evelyn, "Representing Women: The Politics of Minangkabau Adat Writtings," dalam The Journal of Asian Studies, vol. 60, no, 1 (Feb. 2001), hlm. 125-149. 
Dalam kondisi sebagaimana disebutkan, wajar apabila muncul tokohtokoh gerakan perempuan, baik dalam bidang pendidikan maupun politik yang pada intinya memperjuangkan hak-hak perempuan, seperti Rohana Kudus, Rusana Said, Saadah Alim, dan Rahmah el Yunusijjah. Perjuangan Rohana Kudus adalah di bidang pendidikan dengan mendirikan sekolah kerajinan, Amai (Ibu) Setia pada tahun 191, dan juga berjuang melalui media massa. Kemudian, perjuangan politik Rasuna Said dimulai dengan beraktivitas di Sarekat Rakyat (SR) sebagai sekretaris cabang, dan selanjutnya bergabung dengan Soematra Thawalib dan Persatoean Moeslimin Indonesia (PERMI) di Bukittinggi pada tahun 1930. Saadah Alim adalah pejuang emansipasi Minangkabau. Dia menyuarakan pemikirannya agar perempuan Minangkabau ikut serta dalam gerakan perempuan di Jawa dan Indonesia. Sementara itu, Rahmah el Yunusijjah dikategorikan sebagai Muslim modern, yang pemikirannya dicurahkan untuk pembaharuan pendidikan Islam di Minangkabau. 


\section{DAFTAR PUSTAKA}

Blackwood, Evelyn, 'Representing Women: The Politics of Minangkabau Adat Writtings' dalam The Journal of Asian Studies, vol. 60, no, 1 (Feb. 2001).

Ranny Emilia, Studi Konflik dan Perdamaian Memperbaiki Dunia Melalui Tangan-tangan Perempuan, Padang: Prodi Ilmu Hubungan Internasional Unand, 2008.

"Rohana, KAS” dalam Soeara Hindia, 1913.

Schrijvers, Joke dan Els Postel-Coster, 'Minangkabau women: Change in Matrilineal Society,” dalam Archipel, Volume 13, 1977.

Abdullah, Taufik., "Modernization in the Minangkabau World," In C. Holt (Ed.), Culture and Politics in Indonesia, Ithaca: Cornell University, 1972.

Taufik Abdullah, 'Some Notes on the Kaba Tjindua Mato: An Example of Minangkabau Traditional literature dalam Indonesia 9 April 1970.

Taufik Abdullah, 'Adat and Islam: An Examination of Conflic In Minangkabau' dalam Indonesia 2 Oktober 1966. 
